Iegs well drawn up to the abdomen. The temperature was $104 \cdot 6^{\circ} \mathrm{F}$, the skin was hot and dry, the tongue was coated with a silvery white fur in the centre, the tip and edges were red and cracked; the breath was foul ; the respirations were 28 and shallow; and the pulse was 124, but of fair volume. The thoracic and abdominal organs were apparently natural. The right femoral and inguinal glands were much enlarged, though distinct from one another, and they were surrounded by considerable brawny œdema. The whole tumour measured $3 \frac{1}{2}$ in. by $4 \frac{1}{2}$ in. and was extremely tender. The skin overlying it was slightly reddened and not moveable on the surface of the swelling, but no fluctuation could be detected. The lochia were very free, light yellow and sweet. The external os admitted the little finger; the internal $c s$ was dilated to admit the finger, by which means several small bits of placenta and shreds of membrane were removed. The cavity was washed out with a 1 in 3000 perchloride of mercury solution and similar vaginal douches were ordered twice daily. On the 12th, the morning after admission, the patient was seen by Dr. Yersin, who refused to inject her as he considered her case to be hopeless. The temperature had remained high, but the lochia were sweet and the pain in the bubo was slightly less. The urine was dirty yellow, of specific gravity 1020, slightly albuminons, and neutral. On the 13th, though much improved in the morning, she became very restless towards night and at 11 P.M. complained of severe pain in both iliac regions. On examination no swelling was detected. The temperature in the morning was $102.0^{\circ}$ and in the evening was $104 \cdot 8^{\circ}$. On the 14 th there was no more pain in the abdomen, she looked much better, and the bubo was considerably enlarged in size. The temperature in the morning was $103.0^{\circ}$ and in the evening was $102.4^{\circ}$. On the 15 th, the temperature remaining high, she was given $10 \mathrm{gr}$. of antefebrin in brandy at night. This greatly relieved the headache as well as being effectual in reducing the temperature $3^{\circ} \mathrm{F}$. On the 17th the bubo was opened. Caseous pus and blood escaped. Beyond copious sweating she complained of nothing. There was no pain and no other swellings were detected. The temperature in the morning was $99.6^{\circ}$ and in the evening was $101 \cdot 0^{\circ}$. From this time the patient progressed quite favourably. On the 22 nd the incision in the bubo was considerably enlarged and two more suppurating sacs were opened. On April 1st she was discharged well.

Bacteriological examinaticns of her blood were made on March 12th and 16th, but the agar tubes remained perfectly sterile. On March 17th cultures on slanting agar were made from the caseous pus and yielded many colonies of plague bacilli and a few streptococci, which were examined microscopically.

The treatment in this case was practically the same as in Case 1 and needs no further comment.

I have to thank Dr. Bitter of Cairo and Professor Gaffky for their kindness in allowing me to work in their laboratory and for confirming the bacteriological and microscopic investigations of the above cases. I am also indebted to Assistant Surgeons Lafonde, Netscher, and Macgregor of St. George's Hospital, Bombay, for their help in observing these cases clinically.

Bombay.

Wrgan Medical Society.-A meeting of this society was held on Sept. 8th, 1898, Mr. Wm. Berry, F.R.C.S.I., President, being in the chair.-Dr. Blair read a paper on the Serum Treatment of Puerperal Septicrmia, which he illustrated with copious notes from a successful case in his own practice. The usual methods of treatment were also adopted throughout. Anti-streptococcic serum was used. The serum was best employed early in the disease and then towards evening, and in all cases collapse must be watched for and obviated. The belief was expressed that recovery from puerperal septicæmia treated with serum would be more thorough than with other methods alone.Dr. Blair said it was desirable that the serum should be of standard strength and purity so that definite results could be obtained.--In the discussion on the paper the following gentlemen took part: The President, Mr. Parker, Mr. Jones, Mr. Graham, Mr. Monks, Mr. France, and Dr. Rees and Dr. Benson.-Dr. Blair replied.-A vote of thanks to Dr. Blair for his paper was moved by Dr. Benson, seconded by Mr. Monks, and carried unanimously.

\section{Olinital allotes:}

\section{MEDICAL, SURGICAL, OBSTETRICAL, AND} THERAPEUTICAL.

\section{A NOTE ON THE OCCURRENCE OF CARTILAGINOUS AND BONY NODULES OF THE TONSILS.}

By WyatT Wingrave, M.R.C.S. Eng.,

ASSISTAXT SURGEOY AND PATHOLOGIST TO THE CENTRAL LONDON THROA' AND EAIR IIOSPITAI.

IN an article published in THE LANCET of August 13th last Dr. Hugh Walsham drew attention to the existence of cartilage and bone in the faucial tonsil and expressed the opinion that they were vestigial in origin, whilst Dr. Kanthack believed that they were due to some metaplastic process. I am quite of the view that these cartilaginous masses originate in developmental vestiges and have always considered them to be identical with the subpharyngeal cartilage of Luschka, referred to in Macalister's "Anatomy," but with regard to the bony masses in some instances I am inclined to agree with Dr. Kanthack, since they are generally multiple, being often scattered about the substance of the tonsil and they are often associated with morbid changes in that structure. Still, Dr. Walsham's example of transition proves a possible chondral origin.

My experience is that cartilaginous nodules are by no means rare in this situation. Several years ago I exhibited sections at the British Laryngological and Rhinological Association and in January last further examples at the Laryngological Society of London. ${ }^{2}$ These nodules were found accidentally during the microscopical examination of diseased tonsils-mostly chronic hypertrophy-removed from patients below twenty years of age. Dr. Walsham's were, however, associated in two instances with the more mature ages of twenty-seven and fifty years, Deichert's case being as old as seventy-seven years. As in those cases, the cartilage was hyaline and white fibrous, embedded in a dense connective tissue capsule, sometimes occurring in the fibrous "bed" and sometimes in the lymphoid pulp of the tonsil, but never in the lymph nodules or follicles. I have only found calcification in one instance and this was not truly osseous. It is interesting to note that in Dr. Walsham's cases the tonsils were atrophied and that the bony elements were in excess of the cartilaginous. There must be considerable difficulty in forming a true estimate as to the frequency in the occurrence of these " nodules," since they are generally found by accident; still I have no doubt but that a systematic search will prove them to be much commoner than is generally believed. It is not an unusual experience when operating to find considerable resistance to the guillotine quite disproportionate to the density of the tonsil tissue. This I have in several instances proved, by the aid of a pocket lens and the fingers, to be due to the presence of fibrous and cartilaginous tissue, which was confirmed by the microscope. The fact that all my cases were young sub. jects is, perhaps, sufficient explanation for their being solely cartilaginous, since in the second instance described by Dr. Walsham there was partial ossification. That these nodules may as "vestigial rests" be the possible and probable foci of neoplastic changes must not be ignored, and as they are of somewhat more than transcendental interest further research as to their frequency and association may prove valuable.

Devonshire-street, $\mathbf{w}$.

CASE OF LARGE FATTY TUMOUR.

\section{By J. A. Hamilton, M.B., C.M. Edin.,} LIEUTEYAYT, I.M.S.

As cases of very large tumours are comparatively rare nowadays the following may be of interest. I am away from books of reference at present, but $I$ do not think that

1 A Text-book of Human Anatomy, by Alexander Macalister, 1889, p. 596 . 